\title{
EFFECT of hydrocolloids on the quality evaluation of flour based noodles from Horse Chestnut
}

\author{
Syed Insha Rafiq ${ }^{1, a}$, Syed Mansha Rafiq ${ }^{2}$ and D.C. Saxena ${ }^{1}$ \\ ${ }^{1}$ Department of Food Engineering \& Technology, Sant Longowal Institute of Engineering and Technology, Longowal, Punjab ,India \\ ${ }^{2}$ Department of Dairy Technology, National Dairy Research Institute, Karnal (India)
}

\begin{abstract}
The present study was focused to investigate the effects of hydrocolloids (guar gum and xanthan gum) at additional levels $(1 \%, 2 \%$ and $3 \%)$ on the noodle characteristics prepared from horse chestnut flour. The qualities of noodles prepared from horse chestnut flour were compared with wheat flour based noodles in terms of cooking characteristics, textural and sensory properties. The hydrocolloid addition in noodles resulted in improvement of cooking and textural qualities in consistent to control sample. The incorporation of 3\% gum significantly increased cooking properties and the firmness of cooked noodles. The results of the sensory evaluation based on a nine point hedonic scale revealed that apart from the control, noodles with 3\% gum were acceptable to the panellists.
\end{abstract}

Keywords: Horse Chestnut flour, noodles, cooking

\section{Introduction}

Noodles, a traditional staple food in many Asian countries, have been consumed for thousands of years. It is becoming increasingly popular worldwide for its convenience, low cost, availability of various products with desirable sensory attributes having varied taste and texture, beneficial nutrition, and long shelf-life. It is considered as one of the main carbohydrate-based foods generally prepared from wheat flour. Globally, the consumption of wheat noodles is second only to bread $[1,2]$ with nearly $40 \%$ of wheat being processed into noodles in Asia [3, 4]. Noodles are generally prepared by mixing raw materials, dough sheeting, and cutting [5]. Nowadays, noodles can be made from various cereal and non-cereal flours like wheat, rice, buckwheat, millets, etc.

Hydrocolloids are classified as thickening or gelling agents, added to foods for improving the stability and texture of foods [6]. Their high polymeric nature and the interactions among polymer chains results in the improvement of mouth feel and viscosity when dissolved or dispersed in food systems [7]. The presence of hydrocolloids increases the eating experience by improving hardness, cutting force, gumminess, and chewiness in noodle making [8].

Diversification of horse chestnut utilization into a variety of food products would support the national food security. In particular, the use of horse chestnut gives health benefits with respect to its flavonoid, protein, vitamin and mineral content [9]. In addition, the presence of phenolic compounds that function as antioxidants and dietary fibre, also contribute to functional food properties of horse chestnut. Therefore, the present study was performed to identify the cooking and textural characteristics as well as sensorial attributes of noodles prepared from horse chestnut flour. In addition, attempts have been made to improve the noodle-making property of horse chestnut flour by adding hydrocolloids such as guar gum and xanthan gum.

\section{Material and methods}

\subsection{Flour preparation}

Horse Chestnut flour was prepared as per the method reported in our previous study [10].

\subsection{Noodle preparation}

Noodles were prepared following the method described by Yoo et al. [11]. The noodle formulation consisted of $100 \mathrm{~g}$ of native horse chestnut flour and $34 \mathrm{ml}$ of distilled water. Two types of hydrocolloids were added to the flour at levels of $1 \%, 2 \%$ and $3 \%$. Wheat flour was taken as control sample. The prepared dough was placed to rest in a plastic bag for $20 \mathrm{~min}$. After that, the dough was processed through a small noodle machine (Mode JMTD-168/140, Beijing, China) with the roller gap reduced gradually, to get dough sheets. The dimensions of the resultant noodle strands were $1 \mathrm{~mm}$ in width and

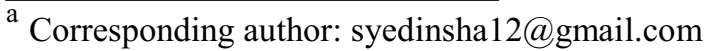


$0.8 \mathrm{~mm}$ in thickness. The noodles were then dried at $60^{\circ} \mathrm{C}$ for $2-3 \mathrm{~h}$ and stored in sealed polyethylene bags.

\subsection{Cooking properties}

\subsubsection{Cooking time}

Noodles $(5 \mathrm{~g})$ were cooked in $100 \mathrm{ml}$ of boiling distilled water in a $250 \mathrm{ml}$ beaker. Noodles were cooked until disappearance of white core as judged by squeezing between two glass slides.

\subsubsection{Cooked weight and solids loss}

The cooking properties of noodles were determined according to the method of Lee et al. [12]. Noodles (10 g) were boiled in distilled water $(150 \mathrm{~mL})$ for $10 \mathrm{~min}$. After boiling, the cooked noodles were allowed to drain for $5 \mathrm{~min}$ using a strainer and the cooked water was collected and dried in an oven $\left(105^{\circ} \mathrm{C}\right)$ and weighed for solids loss. The cooking loss was expressed as a percentage of solid loss during cooking. Cooked noodles were also weighed for gain in cooked weight.

\subsubsection{Water uptake percentage $(\mathrm{g} / 100 \mathrm{~g})$}

The water uptake is the difference in the weight of cooked noodle versus uncooked noodles, expressed as the percentage of weight of uncooked noodles [13].

Cooked noodles were rinsed with cold water and drained for $30 \mathrm{~s}$ then weighed to determine the cooking gain. The analysis indicates the amount of water absorbed by the noodle during cooking process.

\subsection{Textural properties of cooked noodles}

Texture is one of the critical characteristics in quality evaluation of noodles. Elasticity, adhesiveness and firmness are the main parameters that are measured in texture evaluation of noodle [14, 15]. Noodles with smooth, soft and elastic texture are consumed in Japan while in China and Korea firmer texture is preferred [16]. Textural properties of cooked noodles were evaluated by texture profile analysis (TPA) using the TA-XT2 Texture Analyzer (Stable Micro Systems, England) within 5 min after cooking. A single strand of each noodle sample was cut to $2.5 \mathrm{~cm}$ length. A set of five strands of cooked noodles was placed parallel on a flat metal plate and compressed to $70 \%$ of their original height using compression platen probe at a speed of 1.0 $\mathrm{mm} / \mathrm{s}$. From force-time curves of the TPA, hardness, adhesiveness, springiness, cohesiveness, gumminess, chewiness and adhesiveness were determined.

\subsection{Sensory evaluation of noodles}

Sensory evaluation was conducted for the cooked noodle samples and a semi trained panel of twenty five members evaluated the noodles using a 9 point hedonic scale ranging from 1 (extremely disliked) to 9 (extremely liked). The panellists were asked to score for slipperiness, firmness, chewiness, tooth packing, appearance and overall acceptability.

\subsection{Statistical analysis}

The data reported are an average of three replications. Significance was defined at $\mathrm{P}<0.05$ by using Duncan's multiple range test.

\section{Results and discussion}

\subsection{Cooking characteristics of noodles}

Noodles were prepared from horse chestnut flour using hydrocolloids viz. xanthan gum and guar gum in different proportions and were tagged as:

HCNO: Native Horse Chestnut flour noodles

XG1: Noodles with $1 \%$ xanthan gum

XG2: Noodles with $2 \%$ xanthan gum

XG3: Noodles with 3\% xanthan gum

GG1: Noodles with 1\% guar gum

GG2: Noodles with $2 \%$ guar gum

GG3: Noodles with 3\% guar gum

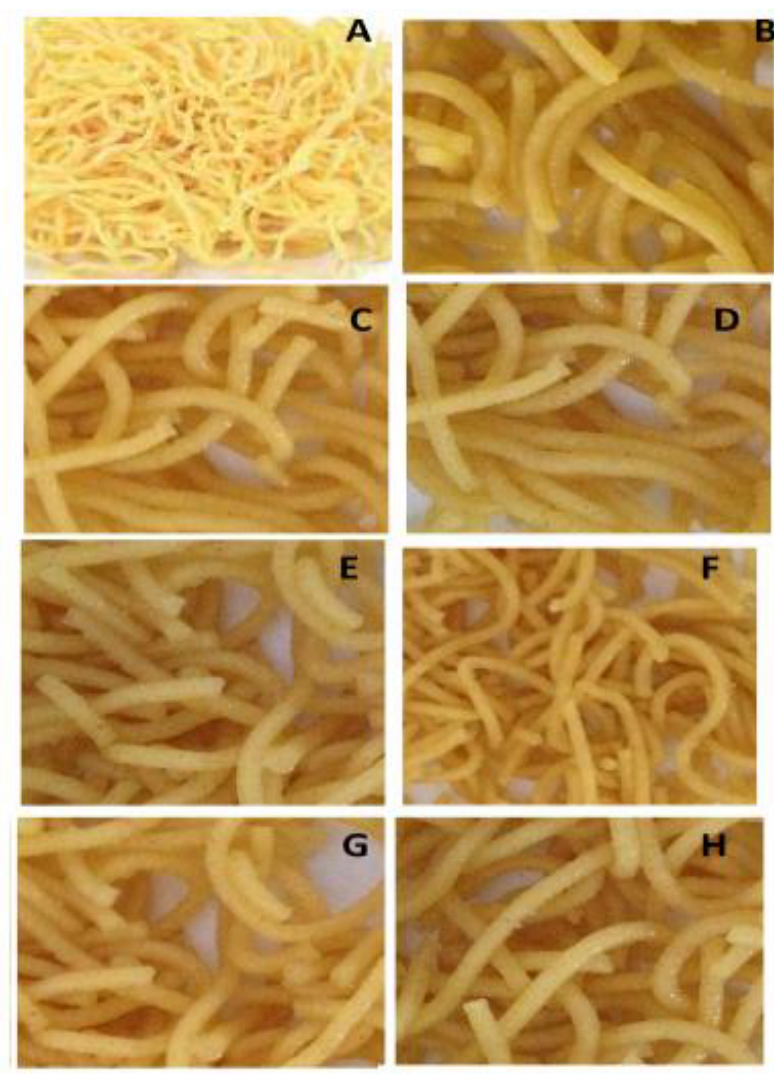

A: Control noodles; B: Noodles with 3\% xanthan gum; C: Noodles with 3\% guar gum; D: Noodles with $2 \%$ guar gum; E: Noodles with 1\% guar gum; F: Native Horse Chestnut flour noodles; G: Noodles with 1\% xanthan gum; H: Noodles with $2 \%$ xanthan gum

Table 1. Cooking properties of noodles

\begin{tabular}{|l|l|l|l|l|}
\hline $\begin{array}{l}\text { Sampl } \\
\text { e }\end{array}$ & $\begin{array}{l}\text { Cooking } \\
\text { time } \\
(\mathrm{min})\end{array}$ & $\begin{array}{l}\text { Cooked } \\
\text { weight }(\%)\end{array}$ & $\begin{array}{l}\text { Cooking loss } \\
(\%)\end{array}$ & $\begin{array}{l}\text { Water } \\
\text { uptake } \\
(\mathrm{g})\end{array}$ \\
\hline $\begin{array}{l}\text { Contr } \\
\text { ol }\end{array}$ & $7.10 \pm 0.16^{\mathrm{b}}$ & $26.14 \pm 0.24^{\mathrm{c}}$ & $4.96 \pm 0.11^{\mathrm{e}}$ & $162 \pm 2.06^{\mathrm{a}}$ \\
\hline
\end{tabular}




\begin{tabular}{|l|l|l|l|l|}
\hline $\begin{array}{l}\text { HCN } \\
\text { O }\end{array}$ & $4.62 \pm 0.12^{\mathrm{f}}$ & $18.43 \pm 0.21^{\mathrm{g}}$ & $10.01 \pm 0.13^{\mathrm{a}}$ & $108 \pm 1.87^{\mathrm{g}}$ \\
\hline XG1 & $5.12 \pm 0.14^{\mathrm{e}}$ & $20.14 \pm 0.18^{\mathrm{f}}$ & $8.76 \pm 0.12^{\mathrm{c}}$ & $117 \pm 1.48^{\mathrm{f}}$ \\
\hline XG2 & $7.01 \pm 0.09^{\mathrm{b}}$ & $23.37 \pm 0.22^{\mathrm{e}}$ & $6.34 \pm 0.09^{\mathrm{d}}$ & $138 \pm 2.01^{\mathrm{c}}$ \\
\hline XG3 & $7.68 \pm 0.11^{\mathrm{a}}$ & $27.87 \pm 0.14^{\mathrm{a}}$ & $4.82 \pm 0.17^{\mathrm{e}}$ & $154 \pm 1.75^{\mathrm{b}}$ \\
\hline GG1 & $5.47 \pm 0.17^{\mathrm{d}}$ & $19.97 \pm 0.19^{\mathrm{f}}$ & $9.01 \pm 0.18^{\mathrm{b}}$ & $118 \pm 1.39^{\mathrm{f}}$ \\
\hline GG2 & $5.86 \pm 0.08^{\mathrm{c}}$ & $24.38 \pm 0.23^{\mathrm{d}}$ & $6.47 \pm 0.12^{\mathrm{d}}$ & $124 \pm 2.09^{\mathrm{e}}$ \\
\hline GG3 & $7.21 \pm 0.16^{\mathrm{b}}$ & $26.72 \pm 0.11^{\mathrm{b}}$ & $5.01 \pm 0.08^{\mathrm{e}}$ & $134 \pm 1.68^{\mathrm{d}}$ \\
\hline
\end{tabular}

Means in a column with same superscript do not differ significantly $(\mathrm{p}<0.05)$.

Cooking quality of noodles is the most important characteristic for consumers and therefore of great importance to processing industry. Cooking characteristics including cooking time, cooked weight, cooking loss and water uptake of noodles are presented in Table 1. Mean cooking time for control, native and $\mathrm{XG}$ and GG noodles varied significantly (Table 1). Cooking time of the XG noodles ranged from 5.12 to $7.68 \mathrm{~min}$ while for GG noodles it ranged from 5.47 to $7.21 \mathrm{~min}$. The water absorption rate was found to be improved in noodles with hydrocolloid than noodles with native HCN flour. Cooking losses are one of the main parameters taken into consideration during the assessment of noodle quality [16]. The results showed less cooking loss in XG3 and GG3 noodle samples. The results also revealed increased weight gain from 20.14 to $27.87 \%$ in $\mathrm{XG}$ noodles and 19.97 to $26.72 \%$ in GG noodles with increased gum concentration. The differences in the cooking quality were attributed primarily to the hydrocolloid fraction that provides as a binder for more retention of water within the noodles.

property and the mouth-feel of noodles since it is concerned as an indicator of the extent of disruption of the noodle structure during mastication. A nonsignificant difference in cohesiveness was observed between the HCNO, XG and GG noodles. The chewiness values for the control, $\mathrm{HCNO}, \mathrm{XG}$ and $\mathrm{GG}$ noodles were observed to have a non significant difference with GC3 sample having the highest value.

\subsection{Textural properties}

The textural properties of the noodles prepared with wheat flour, horse chestnut flour and hydrocolloid blends are shown in Table 2. The textural properties were significantly changed in all the textural parameters except for the adhesiveness and cohesiveness values of control and horse chestnut flour-based noodles ( $p<$ 0.05). In general, the addition of hydrocolloids to horse chestnut flour-based noodles enhanced their firmness values. Though all the samples with hydrocolloids are fair considering the firmness of the noodles but XG3 and GG3 compete favourably with the control sample. The incorporation of hydrocolloid increased the firmness of noodles from 9.93 to $16.2 \mathrm{~N}$ (XG sample) and 9.93 to $15.1 \mathrm{~N}$ (GG sample), respectively. Compared to the values of the control noodles, the firmness of noodles with 3\% hydrocolloids was increased. On the other hand, the control noodles without hydrocolloids exhibited a lower cohesiveness compared to the noodles with added hydrocolloids. Cohesiveness affects the cooking property and the mouth-feel of noodles since it is concerned as an indicator of the extent of disruption of the noodle structure during mastication. A nonsignificant difference in cohesiveness was observed between the HCNO, XG and GG noodles. The chewiness values for the control, HCNO, XG and GG noodles were observed to have a non significant difference with GC3 sample having the highest value.

\begin{tabular}{|c|c|c|c|c|c|}
\hline Sample & Firmness (N) & $\begin{array}{l}\text { Adhesiveness } \\
\text { (N mm) }\end{array}$ & Cohesiveness & Springiness (mm) & $\begin{array}{c}\text { Chewiness } \\
(\mathbf{N} * \mathbf{m m})\end{array}$ \\
\hline Control & $16.21 \pm 1.14^{\mathrm{a}}$ & $0.36 \pm 0.05^{b}$ & $0.58 \pm 0.04^{\mathrm{d}}$ & $0.91 \pm 0.15^{\mathrm{a}}$ & $9.47 \pm 0.15^{\mathrm{c}}$ \\
\hline HCNO & $9.93 \pm 0.89^{f}$ & $0.36 \pm 0.04^{b}$ & $0.57 \pm 0.03^{\mathrm{d}}$ & $0.89 \pm 0.11^{\mathrm{a}}$ & $5.71 \pm 0.12^{\mathrm{f}}$ \\
\hline XG1 & $12.10 \pm 1.11^{\mathrm{de}}$ & $0.49 \pm 0.10^{\mathrm{a}}$ & $0.69 \pm 0.07^{\mathrm{ac}}$ & $0.87 \pm 0.13^{\mathrm{a}}$ & $8.38 \pm 0.08^{3}$ \\
\hline XG2 & $14.23 \pm 1.06^{\mathrm{ac}}$ & $0.50 \pm 0.09^{\mathrm{a}}$ & $0.67 \pm 0.06^{\mathrm{bc}}$ & $0.74 \pm 0.16^{\mathrm{ab}}$ & $9.64 \pm 0.16^{\mathrm{c}}$ \\
\hline XG3 & $16.2 \pm 1.18^{\mathrm{a}}$ & $0.30 \pm 0.01^{\mathrm{b}}$ & $0.64 \pm 0.02^{\text {bcd }}$ & $0.63 \pm 0.18^{\mathrm{ad}}$ & $10.38 \pm 0.14^{b}$ \\
\hline GG1 & $11.24 \pm 1.04^{\mathrm{ef}}$ & $0.52 \pm 0.06^{\mathrm{a}}$ & $0.76 \pm 0.05^{\mathrm{a}}$ & $0.81 \pm 0.14^{\mathrm{a}}$ & $8.58 \pm 0.09^{\mathrm{e}}$ \\
\hline GG2 & $13.46 \pm 1.12^{\mathrm{bcd}}$ & $0.58 \pm 0.07^{\mathrm{a}}$ & $0.67 \pm 0.03^{\mathrm{bc}}$ & $0.66 \pm 0.12^{\mathrm{ac}}$ & $9.15 \pm 0.11^{d}$ \\
\hline GG3 & $15.1 \pm 1.18^{\mathrm{ab}}$ & $0.32 \pm 0.08^{b}$ & $0.71 \pm 0.01^{\mathrm{a}}$ & $0.51 \pm 0.18^{\mathrm{bcd}}$ & $10.87 \pm 0.13^{\mathrm{a}}$ \\
\hline
\end{tabular}

Table 2. Textural properties of cooked noodles

Means in a column with same superscript do not differ significantly $(\mathrm{p}<0.05)$. 
Table 3. Sensory characteristics of cooked noodles

\begin{tabular}{|l|c|c|c|c|c|c|}
\hline Sample & Slipperiness & Firmness & Chewiness & $\begin{array}{c}\text { Tooth } \\
\text { packing }\end{array}$ & Appearance & $\begin{array}{c}\text { Overall } \\
\text { acceptability }\end{array}$ \\
\hline Control & $4.97 \pm 1.54^{\mathrm{bcd}}$ & $8.31 \pm 1.46^{\mathrm{a}}$ & $6.64 \pm 1.43^{\mathrm{ac}}$ & $6.40 \pm 0.67^{\mathrm{a}}$ & $8.50 \pm 0.53^{\mathrm{a}}$ & $8.00 \pm 2.43^{\mathrm{a}}$ \\
\hline HCNO & $5.01 \pm 1.23^{\mathrm{bcd}}$ & $4.10 \pm 1.34^{\mathrm{bc}}$ & $4.68 \pm 1.25^{\mathrm{cd}}$ & $4.11 \pm 0.56^{\mathrm{cde}}$ & $4.44 \pm 0.31^{\mathrm{d}}$ & $5.5 \pm 2.15^{\mathrm{d}}$ \\
\hline XG1 & $6.26 \pm 1.41^{\mathrm{ac}}$ & $5.40 \pm 1.25^{\mathrm{bc}}$ & $5.19 \pm 1.31^{\mathrm{cd}}$ & $4.70 \pm 0.81^{\mathrm{be}}$ & $5.10 \pm 0.46^{\mathrm{d}}$ & $6.80 \pm 1.87^{\mathrm{c}}$ \\
\hline XG2 & $7.78 \pm 1.18^{\mathrm{a}}$ & $6.38 \pm 1.51^{\mathrm{ab}}$ & $6.50 \pm 1.26^{\mathrm{ad}}$ & $5.13 \pm 0.91^{\mathrm{bc}}$ & $6.56 \pm 0.62^{\mathrm{c}}$ & $7.62 \pm 1.64^{\mathrm{b}}$ \\
\hline XG3 & $8.41 \pm 1.34^{\mathrm{a}}$ & $8.5 \pm 1.32^{\mathrm{a}}$ & $8.76 \pm 1.13^{\mathrm{a}}$ & $6.38 \pm 0.76^{\mathrm{a}}$ & $8.67 \pm 0.88^{\mathrm{a}}$ & $8.16 \pm 1.96^{\mathrm{a}}$ \\
\hline GG1 & $6.18 \pm 1.14^{\mathrm{ad}}$ & $4.67 \pm 1.17^{\mathrm{bc}}$ & $6.09 \pm 1.41^{\mathrm{bcd}}$ & $4.89 \pm 0.64^{\mathrm{bd}}$ & $6.42 \pm 0.37^{\mathrm{c}}$ & $6.8 \pm 2.04^{\mathrm{c}}$ \\
\hline GG2 & $7.31 \pm 1.39^{\mathrm{ab}}$ & $6.33 \pm 1.24^{\mathrm{ac}}$ & $7.89 \pm 1.20^{\mathrm{ab}}$ & $5.78 \pm 0.43^{\mathrm{ab}}$ & $7.53 \pm 0.41^{\mathrm{b}}$ & $7.24 \pm 2.51^{\mathrm{b}}$ \\
\hline GG3 & $8.36 \pm 1.28^{\mathrm{a}}$ & $8.13 \pm 1.12^{\mathrm{a}}$ & $8.75 \pm 1.35^{\mathrm{a}}$ & $6.75 \pm 0.51^{\mathrm{a}}$ & $8.64 \pm 0.58^{\mathrm{a}}$ & $8.04 \pm 1.67^{\mathrm{a}}$ \\
\hline
\end{tabular}

Means in a column with same superscript do not differ significantly $(\mathrm{p}<0.05)$.

\subsection{Sensory evaluation}

Sensory evaluation is nearest to a consumer's estimation and remains the most reliable test as it allows the overall characteristics of cooked noodles to be evaluated. As shown in Table 3, the sensory attributes including slipperiness, firmness, chewiness, tooth packing, appearance and overall acceptability differ significantly among the horse chestnut noodles with different levels of xanthan and guar gum and the control noodles.

Native noodles were found to have least score while XG3 and GG3 samples were rated highest for slipperiness, firmness, chewiness, tooth packing and appearance. The overall acceptability of XG3 and GG3 noodles appeared to have non-significant correlation with the control sample. This finding might conclude that using the hydrocolloid as a proportional substitution for horse chestnut flour up to $3 \%$ could obtain the similar quality and pleasant appearance as control wheat flour noodles.

\section{Conclusions}

The study revealed that the noodles produced from horse chestnut flour with different proportions of guar and xanthan gums differed significantly. The hydrocolloids addition in noodles positively modified the cooking and textural quality with increased concentration. The sensory evaluation results indicated that the noodles with 3\% hydrocolloids were highly accepted. Thus, substituting flour with $3 \%$ gum will go a long way to improve noodles quality and make them affordable. Hence, horse chestnut noodles stand a good product with added hydrocolloids so that the attributes like firmness and texture will not only be improved but the product will also be stable for consumption. In a further study, it will be necessary to optimize the appropriate combination of hydrocolloid-flour blends based on their physical characterization and functionality.

\section{References}

[1] X.L. Ding, J.X. Zheng. Steamed bread and noodles in China. In D. J. Martin, \& C. W. Wrigley (Eds.), Proceedings conference cereals international (pp. 35-

40). Melbourne: Royal Australian Chemistry Institute (1991)

[2] S.N. Shin, S.K. Kim, Properties of instant noodle flours produced in Korea. Cereal Foods World, 48, 310-314. (2003)

[3] G.B. Crosbie, The relationship between starch swelling properties, paste viscosity and boiled noodle quality in wheat flours. J. Cereal Sci. 13(2), 145-150 (1991)

[4] G. Hou, Oriental noodles. Adv. Food Nutri. Res. 43, 143-193 (2001)

[5] J. Kruger, R. Matsuo, J. Dick. Pasta and Noodle Technology. American Association of Cereal Chemistry, St Paul, MN (1996)

[6] H.J. Chung, Q. Liu, S.T. Lim. Texture and in vitro digestibility of white rice cooked with hydrocolloids. Cereal Chem. 84, 246-249 (2007)

[7] E.I. Yaseen, T.J. Herald, F.M. Aramouni, S. Alavi. Rheological properties of selected gum solutions. Food Res. Inter. 38, 111-119 (2005)

[8] K.S. Lim, I.K. Hwang. Effects of hydrocolloids on wheat flour rheology. J. Kor. Socie. Food Sci. Nutri. 15, 203-209 (1999)

[9] M. Majeed, M.A. Khan, A. Bashir, A. Hussain. Nutritional Value and Oil Content of Indian HorseChestnut Seed. Global J. Sci. Front. Res. 10(4), 17 (2010)

[10] S.I. Rafiq, S. Singh, D.C. Saxena. Physical, physicochemical and anti-nutritional properties of Horse Chestnut (Aesculus indica) seed. Food Measure. DOI 10.1007/s11694-016-9307-2. (2016).

[11] J. Yoo, Y. Kim, S.H. Yoo, G.E. Inglett, S. Lee. Reduction of rutin loss in 
buckwheat noodles and their physicochemical characterisation. Food Chem. 132, 2107-2111 (2012)

[12] S. Lee, I.Y. Bae, J.H. Jung, K.I. Jang, Y.O. Kim, H.G. Lee. Physicochemical,

textural and noodle-making properties of wheat dough containing alginate. J. Texture Stud. 39 (4), 393-404 (2008)

[13] F.C.F. Galvez, A.V.A. Resurreccion. Reliability of the focus group technique in determining the quality characteristics of mung bean noodles. J. Senso. Stud. 7, 315 (1992)

[14] G.B. Crosbie, W.J. Lambe, H. Tsutsui, R.F. Gilmour. Further evaluation of the flour swelling volume test for identifying wheats potentially suitable for Japanese noodles. J. Cereal Sci. 15, 271-280 (1992) [15] D.M. Miskelly, H.J. Moss. Flour quality requirement for Chinese noodle manufacture. J. Cereal Sci. 3, 379 (1985)

[16] B.K. Dadzie, J.E. Orchard. Routine Post-Harvest Screening of Banana/Plantain Hybrids: Criteria and Methods. Inibap Technical Guidelines (1997) 